\title{
European consensus on essential steps of Minimally Invasive Ivor Lewis and McKeown Esophagectomy through Delphi methodology
}

\author{
Yassin Eddahchouri ${ }^{1}$ (D) - Frans van Workum ${ }^{1}$ - Frits J. H. van den Wildenberg ${ }^{3} \cdot$ Mark I. van Berge Henegouwen $^{2}$. \\ Fatih Polat ${ }^{3}$. Harry van Goor ${ }^{1}$. MIE Delphi Collaboration • Jean-Pierre E. N. Pierie ${ }^{4,5}$ - Bastiaan R. Klarenbeek ${ }^{1}$. \\ Suzanne S. Gisbertz ${ }^{2} \cdot$ Camiel Rosman $^{1}$
}

Received: 30 May 2020 / Accepted: 9 January 2021 / Published online: 19 February 2021

(c) The Author(s) 2021

\begin{abstract}
Background Minimally invasive esophagectomy (MIE) is a complex and technically demanding procedure with a long learning curve, which is associated with increased morbidity and mortality. To master MIE, training in essential steps is crucial. Yet, no consensus on essential steps of MIE is available. The aim of this study was to achieve expert consensus on essential steps in Ivor Lewis and McKeown MIE through Delphi methodology.

Methods Based on expert opinion and peer-reviewed literature, essential steps were defined for Ivor Lewis (IL) and McKeown (McK) MIE. In a round table discussion, experts finalized the lists of steps and an online Delphi questionnaire was sent to an international expert panel (7 European countries) of minimally invasive upper GI surgeons. Based on replies and comments, steps were adjusted and rephrased and sent in iterative fashion until consensus was achieved.

Results Two Delphi rounds were conducted and response rates were $74 \%$ (23 out of 31 experts) for the first and $81 \%$ (27 out of 33 experts) for the second round. Consensus was achieved on 106 essential steps for both the IL and McK approach. Cronbach's alpha in the first round was 0.78 (IL) and 0.78 (McK) and in the second round 0.92 (IL) and 0.88 (McK).

Conclusions Consensus among European experts was achieved on essential surgical steps for both Ivor Lewis and McKeown minimally invasive esophagectomy.
\end{abstract}

Keywords Upper GI · Consensus · Minimally invasive surgery $\cdot$ Esophagectomy $\cdot$ Essential steps

Suzanne S. Gisbertz and Camiel Rosman share senior responsibility.

Collaborators of the MIE Delphi Collaboration are listed in "Acknowledgments."

Yassin Eddahchouri

Yassin.e@live.nl; yassin.eddahchouri@ radboudumc.nl

1 Department of Surgery, Radboud University Medical Center, 618, PO Box 9101, 6500 HB Nijmegen, The Netherlands

2 Department of Surgery, Amsterdam UMC, Cancer Center Amsterdam, University of Amsterdam, Amsterdam, The Netherlands

3 Department of Surgery, Canisius-Wilhelmina Ziekenhuis, Nijmegen, The Netherlands

4 Department of Surgery, Medical Center Leeuwarden, Leeuwarden, The Netherlands

5 Centrum voor Opleiding en Onderwijs Wenckebach, University Medical Center Groningen, Groningen, The Netherlands
Esophageal cancer is the seventh most common cancer worldwide (572,000 cases) and the incidence is increasing [1]. The cornerstone of curative treatment of patients with locally advanced disease consists of neoadjuvant therapy followed by surgical resection. Esophagectomy is a highly complex procedure and morbidity and mortality rates up to $50 \%$ and $8 \%$ are reported, respectively [2]. The use of minimally esophagectomy (MIE) is gaining popularity [3] since it is associated with a lower complication rate and shorter hospital stay than open resection [4-6]. Long-term survival after esophagectomy depends on multiple patient and diseaserelated factors, but also hospital and surgeon volume have shown to affect postoperative outcome [7-10]. Moreover, extensive surgical learning curve effects of MIE on morbidity and mortality have been described [11-13]. This shows that surgical proficiency may play an important role in the outcome of surgery and shortening the learning curve could be beneficial for patient outcomes after introduction of a new surgical procedure. In MIE, several fellowship programs 
and courses aim to improve surgical proficiency and shortening the learning curve. However, surgical techniques are heterogeneous and essential steps of the procedure have not been established, which complicates teaching of a standardized and effective form of MIE. In addition, a consensus on the essential steps of MIE can be a foundation for a widely accepted evidence-based and structured way of training and assessment of surgical technique, which could aid in quality
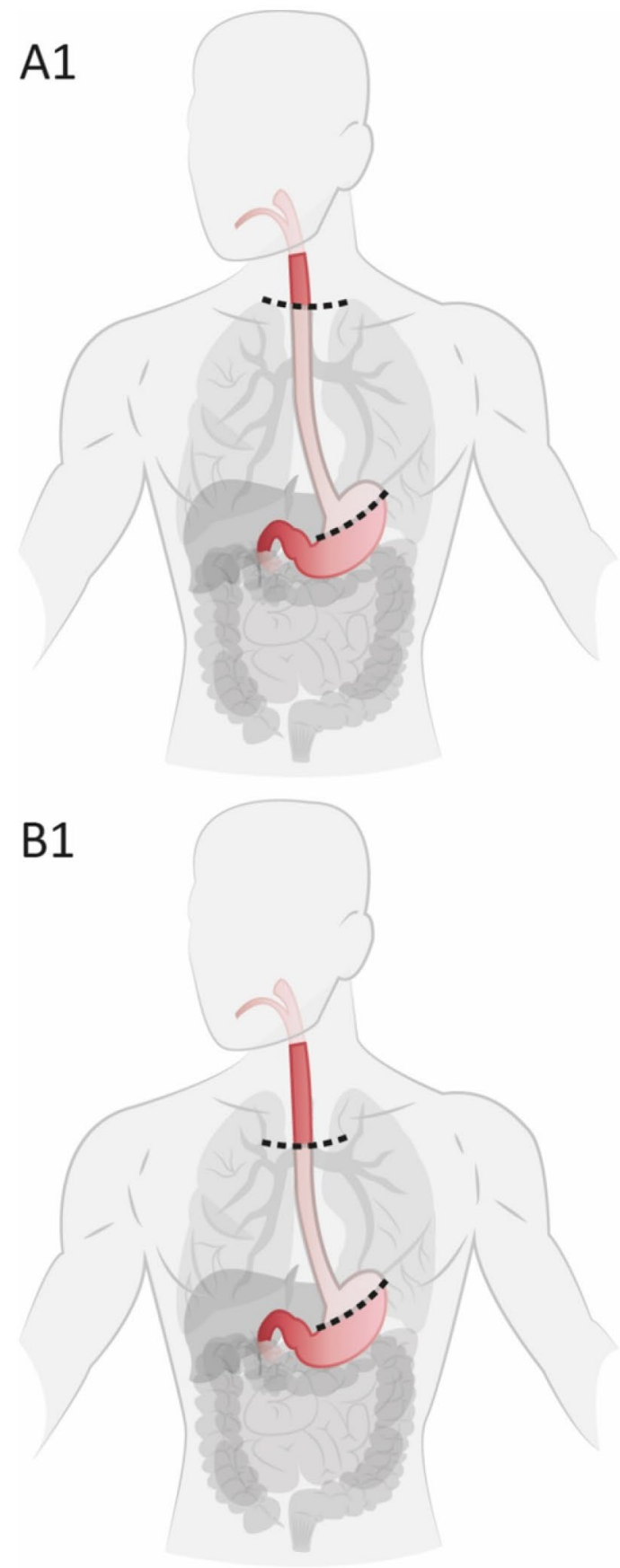

assurance, surgical learning and reducing learning associated morbidity.

Therefore, the primary objective of this study was to achieve international expert consensus on essential steps for both Ivor Lewis (IL) and McKeown (McK) MIE (Fig. 1) by using the Delphi methodology. Since IL and McK are the most preferred MIE approaches [3], both were incorporated in this study.
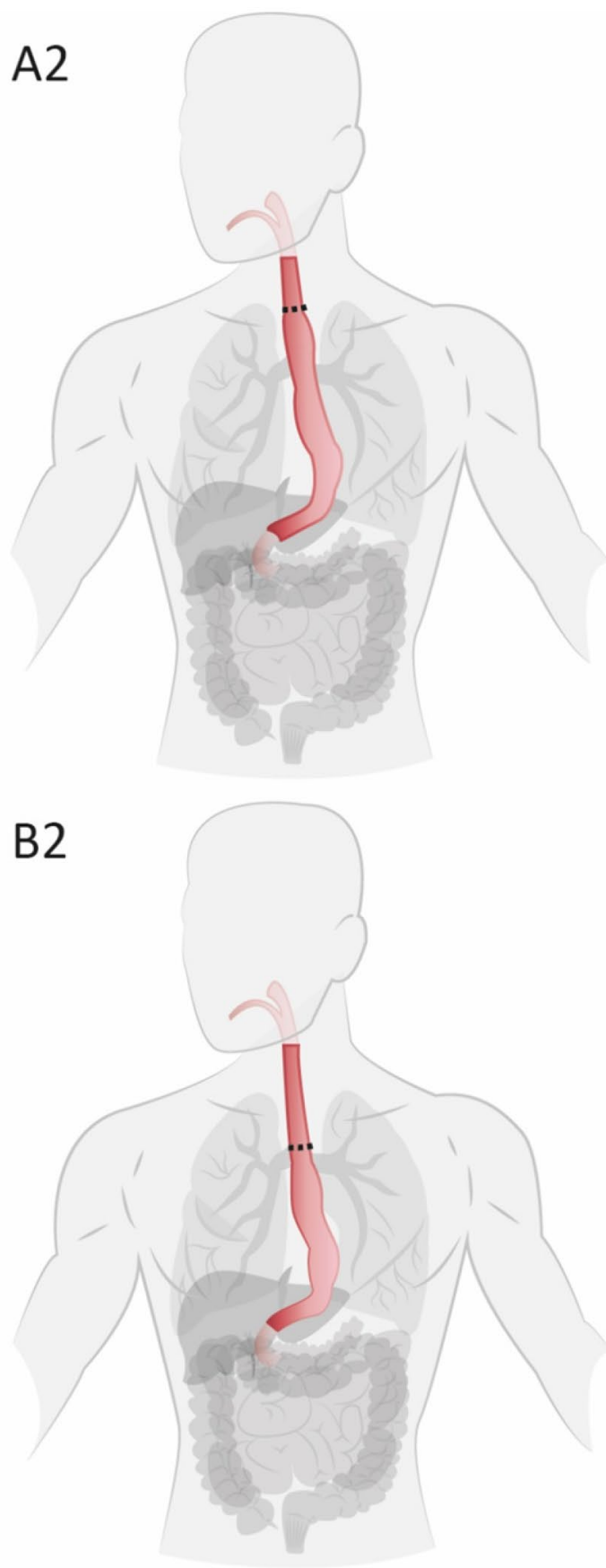

Fig. 1 McKeown and Ivor Lewis esophagectomy. McKeown esophagus and cardia resection (A1) and final location of the anastomosis and gastric tube (A2) and Ivor Lewis resection (B1) and final location (B2). Incisions (e.g., neck incision and mini-thoracotomy) are not shown 


\section{Methods}

\section{Round table meetings}

Led by peer-reviewed literature [14], three practicing surgeons from two high-volume hospitals experienced in thoracolaparoscopic esophagectomies (an average of 100 MIE performed so far), accompanied by one expert in surgical education, determined and defined consecutive steps required to complete MIE. The meeting was recorded to transcribe the steps, which were iteratively sent to the three surgeons for verification and refinement until the surgeons approved the version individually. This final list was used in the Delphi rounds.

\section{Delphi methodology}

The Delphi methodology was used to achieve consensus on the essential steps of both IL and McK MIE (Fig. 1) and has been widely used in determining essential steps of other surgical procedures [15-18]. It is a process in which experts express their ideas using a questionnaire $[19,20]$. Based on the responses and comments, items are adjusted, removed or added, and then resent for another round. This iterative process is ended when consensus is achieved.

\section{Expert panel}

An international panel of practicing MIE surgeons was invited to participate in the Delphi rounds. Experts were selected based on surgical experience and involvement in training and education of surgical residents. A minimum of 100 esophagectomies and at least 3 years of experience in total MIE was required for participation. Based on expertise, involvement in research and education, we invited all members of the European Minimally Invasive Oesophagectomy (MIO) Think Tank as well as the majority of the Dutch high-volume centers. A total of 36 surgeons were invited to participate in the first round of this study. Experts were contacted by a personal invitation email, in which the aim of this study was elaborated. Then the survey was sent, followed by a personal reminder three to four weeks thereafter. Only surgeons that actively declined participation or those that did not meet inclusion criteria were not invited for next rounds.

\section{Ivor Lewis vs. McKeown}

Since IL and McK resection are the most common MIE approaches performed [3], an individual list of essential steps was constructed for both procedures. The two lists contained several anastomotic techniques (i.e., hand-sewn end-to-end (E/E), stapled side-to-side (S/S) and stapled endto-side (E/S) anastomosis for the IL approach and hand-sewn $\mathrm{E} / \mathrm{S}$, hand-sewn E/E, stapled E/S and stapled S/S for the $\mathrm{McK}$ approach). All participants received both lists and were asked to rate the MIE approach(es) and anastomotic technique(s) they regularly practiced. An anastomotic technique was excluded when rated by less than five participants. Additional procedures (i.e., nasogastric tube and jejunostomy placement) were incorporated as well.

\section{Delphi round one}

An online questionnaire and database system [www.casto redc.com] was used to send out the Delphi questionnaire and to collect the data and comments. Panel members were asked to rate the importance of each step in MIE on a Likerttype scale; $1-5$ (strongly disagree to strongly agree). Furthermore, they were asked to comment on their ratings and on any missing steps.

\section{Delphi round two}

Responses and comments on round one were collected and analyzed. Based on the ratings and comments, steps were modified and resent to the same participants. The main modifications in the second round were rephrasing ("redefined") steps and adding new ("new") ones. A redefined step was a step which was changed regarding content, or which was split into multiple steps or vice versa. Modification of the steps was performed in two separate sessions by expert surgeons of two Dutch high-volume centers ( $>75$ MIE annually). If less than $80 \%$ of participants rated a step as 4 ("agree") or 5 ("strongly agree"), the calculated percentages were presented back to the panel members as well. Steps that reached more than $80 \%$ agreement could also still be modified based on the comments and resent for another rating to improve agreement.

\section{Determination of consensus}

Consensus among panel members was determined by using Cronbach's alpha [21], which is a measure for how closely related the responses of the experts are. Missing datapoints were replaced by mean values. For scales used in research tools and for comparing groups, an Alpha of 0.7-0.8 is considered satisfactory [21]. A Cronbach's alpha of $>0.7$ was deemed satisfactory for the educational and research purpose of this study. Steps were included as an essential step when they were rated as 4 (agree) or 5 (strongly agree) by more than $80 \%$ of panel members. A new round was conducted when new steps were proposed by panel members, even when Alpha exceeded 0.7. 


\section{Results}

Three out of 36 surgeons did not perform total MIE and two surgeons of the remaining 33 did not meet the inclusion criteria at the time of the first invitation and were therefore excluded. In round one, 23 out of 31 (74\%) experts from 17 hospitals and seven different countries responded to the questionnaire. The IL questionnaire was completed by 21 (91\%) participants and the McK questionnaire by 16 (70\%). Seven surgeons (30\%) responded only to the IL questionnaire, two (9\%) responded only to the McK questionnaire and $14(61 \%)$ responded to both.

In the second round, a response rate of $81 \%$ was reached (27 out of 33 experts). The IL and McK questionnaires were completed by 24 (89\%) and 18 (67\%) respondents, respectively. Nine (33\%) participants responded only to the IL questionnaire, three (11\%) responded only to the $\mathrm{McK}$ questionnaire and 15 (56\%) responded to both. Participating surgeons had a mean experience in MIE of ten years and had performed more than 300 MIEs in their career so far (Table 1).

In the first round Cronbach's alpha reached 0.78 and 0.78 for IL and McK essential steps, respectively. In the second round Cronbach's alpha reached 0.92 for IL and 0.88 for McK steps.

\section{Ivor Lewis steps}

Due to the low incidence of the use of the IL hand-sewn $\mathrm{E} / \mathrm{E}$ technique (one expert), the anastomotic steps of this technique were excluded. After the first round, 68 of the remaining 126 steps were directly included based on both the results and comments of the respondents. Forty-five steps were redefined to be resent for another rating, seven were resent without redefinition, five were excluded and 34 new steps were added. Some steps were redefined into multiple smaller steps or vice versa. For each step, the percentage of agreement and the action after round one ("redefined", "resent", "included" or "excluded") are shown in detail in Online Appendix 1. In the second round, 81 steps (40 "redefined", seven "resent" and 34 "new" steps) were

Table 1 Expert characteristics

\begin{tabular}{lccllc}
\hline Experience & \multicolumn{2}{l}{ Ivor Lewis } & & \multicolumn{2}{l}{ McKeown } \\
\cline { 2 - 3 } \cline { 6 - 6 } \cline { 5 - 6 } & Mean & $95 \%$ CI & & Mean & $95 \%$ CI \\
\hline Surgery (years) & 17.3 & $13.6-21.0$ & & 14.8 & $10.6-19.0$ \\
Esophageal surgery (years) & 14.6 & $11.8-17.4$ & & 13.4 & $9.8-17.1$ \\
MIE (years) & 10.0 & $7.5-12.4$ & & 9.9 & $6.6-13.2$ \\
MIEs performed so far (n) & 340 & $248-432$ & & 335 & $212-457$ \\
\hline
\end{tabular}

MIE minimally invasive esophagectomy sent to the participants, of which 43 were excluded and 38 were included, resulting in a total of 106 included (Table 2) and 48 excluded steps (Table 3). For all steps in the second round, the origin ("redefined", "resent" or "new"), percentage of agreement and action after round two ("included" or "excluded") are shown in detail in Online Appendix 2.

\section{McKeown steps}

Due to the low incidence of the use of the stapled E/S (one expert) and stapled $\mathrm{S} / \mathrm{S}$ technique (two experts), the steps of these techniques were excluded. After the first round, 64 of the remaining 116 steps were directly included in the final list of essential steps. Forty-one steps were redefined to be resent for another rating, ten were resent without redefinition, one was excluded and 37 new steps were added. The details of round one are shown in Online Appendix 3. In the second round, 87 steps (40 "redefined", ten "resent" and 37 "new" steps) were sent to the participants. In this round, 45 steps were excluded and 42 were included, resulting in a total of 106 included (Table 4) and 46 excluded steps (Table 5). The details of round two are shown in Online Appendix 4.

\section{Discussion}

This is the first study describing consensus-based essential steps of minimally invasive esophagectomy for cancer. Consensus among European MIE experts was achieved on essential surgical steps for both Ivor Lewis and McKeown. This resulted in a distinct list of essential steps with 106 steps for each approach, describing both procedures in detail.

\section{Strengths and limitations}

One of the strengths of this study is that the adjustments after the first round were made at two separate occasions with local experts from two high-volume hospitals. A significant increase in consensus was reached after the second round, which demonstrated a high consensus rate compared to similar studies [15-17]. Despite a percentage of agreement $\geq 80$ being the main perquisite for inclusion, comments have been used to refine or rephrase steps to improve consensus, even when this percentage was reached. Another strength of the study is that compared to the literature, and despite the length of the questionnaires (81-126 items each), high response rates of $74 \%$ and $81 \%$ were obtained for both the first and second round [16-18, 22, 23]. The international expert panel, greatly involved in education, with a vast experience in MIE and the high response rates make these lists likely to be internationally widely supported. To ensure the widely use and 
Table 2 Ivor Lewis final key step list

Included Ivor Lewis steps

Preparation for laparoscopic phase

1. Make sure prophylactic antibiotics are administered and repeated after 4-6 h

2. Insert urinary catheter

3. Position patient in supine position and position patient's extremities

4. Create sterile field

5. Position operating team and position laparoscopy monitors

6. Position patient in reverse Trendelenburg

Abdominal access

7. Place 1st abdominal port and establish $12-15 \mathrm{mmHg}$ pneumoperitoneum

8. Place additional ports under direct vision

9. Place liver retractor

Abdominal inspection

10. Perform diagnostic/staging laparoscopy

Mobilization of greater curvature

11. Create access to lesser sac through gastrocolic ligament

12. Dissect gastrocolic ligament along greater curvature just cranial of the transverse colon. (including preparation for later omentoplasty)

13. Dissect retrogastric adhesions onto the left crus

14. Complete dissection of gastrocolic ligament by dissecting from initiation site back to the pylorus/proximal duodenum

15. Dissect retrogastric adhesions along the pancreas to the lesser curvature

Mobilization of lesser curvature

16. Determine dissection site of gastrohepatic ligament. (3-4 side branches of right gastric artery/vein)

17. Open gastrohepatic ligament onto the stomach

18. Dissect gastrohepatic ligament along lesser curvature onto right bundle of the right crus

19. Make sure stomach is completely mobilized onto the diaphragm

Access to celiac trunk

20. Dissect peritoneum at the upper margin of the pancreas to create proper access to the celiac trunk

Identification and dissection of abdominal vessels

21. Identify right gastroepiploic vessels/arcade

22. Dissect left gastroepiploic artery and short gastric vessels

23. Free pedicle of right gastroepiploic artery of surrounding tissue to create more length

24. Identify right gastric artery

25. Identify common hepatic artery

26. Identify splenic artery

27. Identify left gastric artery and vein

28. Transect left gastric vein

29. Transect left gastric artery

Abdominal lymph node dissection

30. Dissect common hepatic artery nodes

31. Dissect left gastric artery nodes

32. Dissect celiac trunk nodes

33. Dissect proximal splenic artery nodes

34. Dissect left paracardial nodes

35. Dissect right paracardial nodes

Mobilization of distal esophagus in the hiatus

36. Dissect peritoneum of distal esophagus circumferentially

37. Transect phrenoesophageal ligaments 
Table 2 (continued)

Included Ivor Lewis steps

Creation of gastric tube

38. Determine where to start stapling

39. Place and fire first linear stapler

40. Successively fire other linear staplers

41. Make sure superior portion of the gastric tube and the distal portion of the cardia are properly (re)attached

42. Check for hemostasis along staple line

43. Check viability of gastric tube

Final abdominal inspection

44. Perform final abdominal inspection (e.g., hemostasis)

Removal of abdominal trocars, liver retractor and port closure

45. Remove trocars

46. Remove liver retractor

47. Close ports

Preparation for thoracoscopic phase

48. Position patient in preferred position (prone/semiprone/left-lateral/left-decubitus) and position patient's extremities

49. Map thorax, including scapula margins

50. Create sterile field

51. Position operating team

52. Position thoracoscopy monitors

Thoracic access

53. Place 1st thoracic port

54. Insufflate $\mathrm{CO} 2$ up to $5-8 \mathrm{mmHg}$

55. Place additional ports under direct vision

Mobilization of thoracic esophagus

56. Dissect inferior pulmonary ligament

57. Dissect the pleura and mobilize the esophagus (right ventral side) along the pericardium to the level of the carina/azygos vein

58. Identify right main bronchus

59. Identify left main bronchus

60. Dissect the pleura alongside the azygos vein (from arcus azygos vein on to the level of the diaphragm)

Identification and dissection of thoracic vessels

61. Transect the arcus of the azygos vein

62. Dissect peri-esophageal aorta side branches and lymph vessels

Thoracic lymph node dissection

63. Dissect subcarinal lymph nodes

64. Dissect middle mediastinal paraesophageal lymph nodes

65. Dissect lower mediastinal paraesophageal lymph nodes

66. Dissect right pulmonary ligament lymph nodes

Thoracotomy and removal of specimen

67. Make sure esophagus is completely mobilized

68. Transect the esophagus

69. Pull esophagus and cardia and attached gastric tube into thoracic cavity

70. Perform a mini-thoracotomy

71. Place wound protector

72. Separate gastric tube from esophagus and cardia

73. Remove esophagus and cardia from thoracic cavity

Thoracic stapled E/S anastomosis

74. Make sure staple line of the gastric tube is still on the right/lateral side 
Table 2 (continued)

Included Ivor Lewis steps

75. Introduce and secure anvil into the esophagus

76. Open the tip of the gastric tube

77. Introduce circular stapler into gastric tube

78. Extend integrated trocar of the stapler through esophageal wall and connect stapler to anvil

79. Fire stapler

80. Inspect doughnuts

81. Dissect omental attachments to the surplus tip of the gastric tube

82. Dissect surplus tip of the gastric tube and remove tip from thoracic cavity

Thoracic stapled $\mathrm{S} / \mathrm{S}$ anastomosis

83. Make sure staple line of the gastric tube is still on the right/lateral side

84. Open gastric tube on the side of the omentum, about 5 centimeters caudal to the tip

85. Introduce linear stapler into the gastric tube and into esophagus

86. Fire stapler

87. Close remaining opening

Omentoplasty

88. Perform omentoplasty at anastomotic site

Placement of drains

89. Place a chest drain

90. Position mediastinal drain

91. Place the drain trough the ventrolateral thoracic wall and secure drain to the skin

Irrigation and inspection

92. Check for hemostasis

93. Inspect recruited right lung before closing (i.e., position, rotation and trauma)

Removal of trocars and port/thoracotomy closure

94. Remove trocars

95. Close thoracotomy

96. Close remaining ports

Placement of nasogastric tube

97. Make sure nasogastric tube has been placed

98. Make sure nasogastric tube does not interfere with esophageal transection site and during tubulation of stomach Jejunostomy placement

99. Identify ligament of Treitz

100. Identify jejunostomy site about $20-40 \mathrm{~cm}$ distally of ligament of Treitz

101. Identify efferent and afferent loop

102. Identify jejunostomy site on the abdominal wall

103. Perform jejunostomy

104. Secure jejunum to abdominal wall

105. Test patency of the catheter

106. Secure catheter to the skin 
Table 3 Excluded Ivor Lewis steps
Ivor Lewis steps excluded after Delphi round 1 and 2

Preparation for laparoscopic phase

1. Make sure preferred anesthetic devices are in place

2. Map abdomen

3. Mold vacuum mattress and evacuate air

Mobilization of greater curvature

4. Identify mesocolon

5. Mobilize proximal duodenum until gastroduodenal artery is visible $\quad 75$

6. Perform additional Kocher maneuver if needed

Identification and dissection of abdominal vessels

7. Transect distal branches of the right gastric artery

8. Identify proper hepatic artery 63

9. Identify portal vein 46

Abdominal lymph node dissection

10. Dissect hepatoduodenal ligament nodes $\quad 42$

11. Dissect distal splenic artery nodes $\quad 42$

12. Dissect splenic hilum nodes $\quad 8$

13. Place clamp on chest drain tube (if al already in place and if already connected to reservoir) $\quad 48$

Mobilization of distal esophagus in the hiatus

14. Open left pleura

15. Open right pleura

Creation of gastric tube

16. Oversew staple line

Mobilization of esophagus

17. Retract right lung

18. Transect left and right vagus nerve $\quad 75$

19. Open and dissect left pleura $\quad 38$

Identification and dissection of thoracic vessels

20. Transect right bronchial artery

21. Identify and dissect thoracic duct $\quad 50$

Thoracic lymph node dissection.

22. Dissect left upper paratracheal lymph nodes $\quad 25$

23. Dissect right upper paratracheal lymph nodes 38

24. Dissect left lower paratracheal lymph nodes $\quad 46$

25. Dissect right lower paratracheal lymph nodes $\quad 54$

26. Dissect lymph nodes at aortopulmonary window 33

27. Dissect upper mediastinal paraesophageal lymph nodes $\quad 71$

28. Dissect left pulmonary ligament lymph nodes $\quad 71$

29. Completely clear the aorta of lymphatic tissue $\quad 63$

Thoracotomy and removal of specimen

30. Use specimen pack

Thoracic stapled E/S anastomosis

31. Measure length of gastric tube

32. Make sure proximal esophagus is open (only necessary when transection done by stapler)(o) 56

33. Excise surplus cuff of the distal side of the proximal esophagus 50

34. Move camera to a port closer to the anastomotic site $\quad 63$

35. Place additional sutures along this staple line. (tip gastric tube) $\quad 44$

Thoracic stapled S/S anastomosis

36. Measure length of gastric tube

37. Make sure proximal esophagus is open (only necessary when transection done by stapler)

38. Place two stitches on lateral sides of esophagus to pull esophagus on stapler 25

39. Dissect omental attachments to the surplus tip of the gastric tube 
Table 3 (continued)

\begin{tabular}{lc}
\hline Ivor Lewis steps excluded after Delphi round 1 and 2 & $\%$ agree \\
\hline 40. Dissect surplus tip of the gastric tube and remove tip from thoracic cavity & 67 \\
41. Place additional sutures along this staple line. (tip gastric tube) & 50 \\
Omentoplasty and/or pleuroplasty & \\
42. Perform pleuroplasty at anastomotic site. (fixation of anastomosis beneath plural flap) & 50 \\
Irrigation and inspection & 38 \\
43. Irrigate thoracic cavity & 58 \\
44. Check for chyle leak & \\
Placement of nasogastric tube & 75 \\
45. Advance nasogastric tube past anastomosis, under direct vision if possible & \\
Jejunostomy placement & 50 \\
46. Position patient in Trendelenburg & 79 \\
47. Place extra anti-rotational stitches & \\
Hiatal approximation & 50 \\
48. Approximate hiatus & \\
\hline
\end{tabular}

support of the future assessment tools, we incorporated multiple anastomotic techniques into the questionnaires. A limitation might be that participants were asked to rate the techniques they used "on a regular basis" which could have been interpreted differently by the participants. Due to the lack of expert input on the excluded techniques (IL hand-sewn E/E, McK stapled E/S and stapled S/S), we were not able to construct a consensus-based list of these steps. Another limitation is that in both rounds datapoints were missing (nine and seven percent for first and second round, respectively). Missing datapoints were replaced by respondents' mean values to calculate Cronbach's alpha. This method has been previously described in the literature [15]. Since sufficient consensus rates were already achieved, we believe, like in other studies, inclusion and exclusion of steps in round one was justified [20]. Finally, all experts in this study were European. Despite seven different countries were represented, the results of this study may not be easily translated to other countries and continents.

The lists of essential steps that were created present us with a detailed format that can be used to standardize MIE. In addition, it provides a starting point for developing procedure-specific assessment tools for both the entire as well as certain parts of the operation. Since final mastery of the procedure comes literally step-by-step, a validated assessment tool for specific parts of the procedure would facilitate specific and structured feedback for residents, fellows and surgeons. This will help to objectively evaluate and assure a surgeons' proficiency and might potentially shorten the learning curve and, more importantly, diminish the learning associated morbidity and mortality. In bariatric surgery, patients operated by surgeons in the top quartile of skills seem less likely to develop overall complications as compared to the bottom quartile [24]. Moreover, in complex oncologic procedures technical performance among credentialed surgeons varies substantially, which is significantly associated with clinical and pathological outcomes [25]. This emphasizes the need to improve one's surgical skills as fast and efficient as possible, especially in complex oncologic procedures like MIE. Procedure-specific assessment tools differentiate well between different skills levels and they seem to be more suitable for summative assessment than global rating scales [26]. For example, the procedure-specific assessment tool in laparoscopic cholecystectomy seemed to better differentiate between novice, intermediate and almost competent trainees than the OSATS and GOALS. Since complex procedures, like MIE, are taught to surgeons that already have surgical experience in other procedures, technical differences between novice and expert surgeons might be subtler. Therefore, a specific assessment tool may be more suitable to allow for a unique insight in the dependence between different levels of skills and outcome of surgery in minimally invasive esophagectomy.

\section{Conclusion}

In this study, we described consensus-based essential steps of minimally invasive esophagectomy for cancer. Future perspectives include the development and validation of an assessment tool targeting essential steps associated with clinically relevant outcome parameters. 
Table 4 McKeown final key step list

Included McKeown steps

Preparation for thoracoscopic phase

1. Make sure prophylactic antibiotics are administered and repeated after 4-6 h

2. Position patient in preferred position (prone/semiprone/left-lateral/left-decubitus) and position patient's extremities

3. Map thorax, including scapula margins

4. Create sterile field

5. Position operating team and position thoracoscopy monitors

Thoracic access

6. Place 1st thoracic port

7. Insufflate $\mathrm{CO}_{2}$ up to $5-8 \mathrm{mmHg}$

8. Place additional ports under direct vision

Mobilization of thoracic esophagus

9. Dissect inferior pulmonary ligament

10. Dissect the pleura and mobilize the esophagus (right, ventral side) along the pericardium to the level of the superior thoracic aperture

11. Identify right main bronchus

12. Identify left main bronchus

13. Dissect the pleura alongside the azygos vein from the level of the diaphragm to the superior thoracic aperture

14. Make sure esophagus is completely mobilized

Identification and dissection of thoracic vessels

15. Transect the arcus of the azygos vein

16. Dissect peri-esophageal aorta side branches and lymph vessels

Thoracic lymph node dissection

17. Dissect subcarinal lymph nodes

18. Dissect upper mediastinal paraesophageal lymph nodes

19. Dissect middle mediastinal paraesophageal lymph nodes

20. Dissect lower mediastinal paraesophageal lymph nodes

21. Dissect right pulmonary ligament lymph nodes

Irrigation and inspection

22. Check for hemostasis

23. Inspect recruited right lung before closing (i.e., position, rotation and trauma)

Removal of trocars and port closure

24. Remove trocars

25. Close ports

Preparation for laparoscopic phase

26. Position patient in supine position and position patients extremities

27. Create sterile field

28. Position operating team and position laparoscopy monitors

29. Position patient in reverse Trendelenburg

Abdominal access

30. Place 1st abdominal port and establish $12-15 \mathrm{mmHg}$ pneumoperitoneum

31. Place additional ports under direct vision

32. Place liver retractor

Abdominal inspection

33. Perform diagnostic/staging laparoscopy

Mobilization of greater curvature

34. Create access to lesser sac through gastrocolic ligament

35. Dissect gastrocolic ligament along greater curvature just cranial of the transverse colon (including preparation for later omentoplasty)

36. Dissect retrogastric adhesions onto the left crus 
Table 4 (continued)

Included McKeown steps

37. Complete dissection of gastrocolic ligament by dissecting from initiation site back to the pylorus/proximal duodenum

38. Dissect retrogastric adhesions along the pancreas to the lesser curvature

Mobilization of lesser curvature

39. Determine dissection site of gastrohepatic ligament (3-4 side branches of right gastric artery/vein)

40. Open gastrohepatic ligament onto the stomach

41. Dissect gastrohepatic ligament along lesser curvature onto right bundle of the right crus

42. Make sure stomach is completely mobilized onto the diaphragm

Access to celiac trunk

43. Dissect peritoneum at the upper margin of the pancreas to create proper access to the celiac trunk

Identification and dissection of abdominal vessels

44. Identify right gastroepiploic vessels/arcade

45. Dissect left gastroepiploic artery and short gastric vessels

46. Free pedicle of right gastroepiploic artery of surrounding tissue to create more length

47. Identify right gastric artery

48. Identify common hepatic artery

49. Identify splenic artery

50. Identify left gastric artery and vein

51. Transect left gastric vein

52. Transect left gastric artery

Abdominal lymph node dissection

53. Dissect common hepatic artery nodes

54. Dissect left gastric artery nodes

55. Dissect celiac trunk nodes

56. Dissect proximal splenic artery nodes

57. Dissect left paracardial nodes

58. Dissect right paracardial nodes

Mobilization of distal esophagus in the hiatus

59. Dissect peritoneum of distal esophagus circumferentially

60. Transect phrenoesophageal ligaments

Final abdominal inspection

61. Perform final abdominal inspection (e.g., hemostasis)

Removal of abdominal trocars and port closure

62. Remove trocars

63. Remove liver retractor

64. Close ports

Cervical mobilization and transection of esophagus

65. Make skin incision anteriorly of the left sternocleidomastoid muscle

66. Divide subcutaneous tissue and platysma muscle

67. Retract sternocleidomastoid muscle and carotid sheath laterally

68. Retract larynx and trachea medially

69. Dissect esophagus away from trachea with preservation of left recurrent laryngeal nerve

70. Dissect esophagus circumferentially of remaining surrounding tissue

71. Make sure esophagus is completely mobilized

72. Transect the esophagus

Mini-laparotomy

73. Perform a mini-laparotomy ${ }^{\mathrm{a}}$ 
Table 4 (continued)

Included McKeown steps

Creation of gastric tube

74. Determine where to start stapling

75. Place and fire first linear stapler

76. Successively fire other linear staplers

77. Check for hemostasis along staple line

78. Check viability of gastric tube

Cervical introduction of gastric tube and removal of specimen

79. Attach a strand or drain or any other guiding device to the esophagus/specimen ${ }^{\mathrm{a}}$

80. Pull esophagus/specimen into abdominal cavity/through mini-laparotomy ${ }^{a}$

81. Make sure to maintain a portion of the strand or drain in the neck ${ }^{\mathrm{a}}$

82. Attach superior portion of the gastric tube to the strand or drain or any other guiding device ${ }^{\mathrm{a}}$

83. Make sure superior portion of the gastric tube and the distal portion of the cardia are properly (re)attached ${ }^{\text {b }}$

84. Pull gastric tube into thoracic cavity until you reach cervical anastomotic site ${ }^{\mathrm{c}}$

85. Remove distal esophagus and $\operatorname{cardia}^{\mathrm{c}}$

86. Make sure staple line of the gastric tube is still on the right/lateral side ${ }^{c}$

Cervical hand-sewn E/S anastomosis

87. Make sure proximal esophagus is open (only necessary when transaction was done by stapler)

88. Create an opening in the gastric tube for the anastomosis

89. Create a sutured anastomosis

90. Dissect surplus tip of the gastric tube

Cervical hand-sewn E/E anastomosis

91. Dissect tip of the gastric tube

92. Create a sutured anastomosis

Wound closure

93. Close cervical wound

94. Close mini-laparotomy ${ }^{a}$

Placement of drains

95. Place a chest drain

Placement of nasogastric tube

96. Make sure nasogastric tube has been placed

97. Make sure nasogastric tube does not interfere with esophageal transection site and during tubulation of stomach

98. Advance nasogastric tube past anastomosis, under direct vision if possible

Jejunostomy placement

99. Identify ligament of Treitz

100. Identify jejunostomy site about $20-40 \mathrm{~cm}$ distally of ligament of Treitz

101. Identify efferent and afferent loop

102. Identify jejunostomy site on the abdominal wall

103. Perform jejunostomy

104. Secure jejunum to abdominal wall

105. Test patency of the catheter

106. Secure catheter to the skin

${ }^{a}$ In case of removing specimen abdominally

${ }^{\mathrm{b}}$ In case of removing specimen through neck incision

${ }^{\mathrm{c}}$ Both 
Table 5 Excluded McKeown steps

McKeown steps excluded after Delphi round 1 and 2

Preparation for thoracoscopic phase

1. Make sure preferred anesthetic devices are in place

2. Insert urinary catheter

Mobilization of thoracic esophagus

3. Retract right lung

4. Transect left and right vagus nerve

5. Open and dissect left pleura

Identification and dissection of thoracic vessels

6. Transect right bronchial artery

7. Identify and dissect thoracic duct

Thoracic lymph node dissection

8. Dissect left upper paratracheal lymph nodes.

9. Dissect right upper paratracheal lymph nodes.

10. Dissect left lower paratracheal lymph nodes.

11. Dissect right lower paratracheal lymph nodes.

12. Dissect lymph nodes at aortopulmonary window.

13. Dissect left pulmonary ligament lymph nodes.

14. Completely clear the aorta of lymphatic tissue.

Irrigation and inspection

15. Irrigate thoracic cavity

16. Check for chyle leak

Preparation for laparoscopic phase

17. Map abdomen

18. Mold vacuum mattress and evacuate air

Mobilization of greater curvature

19. Identify mesocolon

20. Mobilize proximal duodenum until gastroduodenal artery is visible

21. Perform Kocher maneuver

Identification and dissection of abdominal vessels

22. Transect distal branches of the right gastric artery

23. Identify proper hepatic artery

24. Identify portal vein

Abdominal lymph node dissection

25. Dissect hepatoduodenal ligament nodes

26. Dissect distal splenic artery nodes

27. Dissect splenic hilum nodes

Mobilization of distal esophagus in the hiatus

28. Open left pleura

29. Open right pleura

Cervical mobilization and transection of esophagus

30. Transect the omohyoid muscle

31. Identify the left recurrent laryngeal nerve

Identification and dissection of cervical vessels

32. Identify middle thyroid vein

33. Identify inferior thyroid artery

34. Transect the inferior thyroid artery

35. Transect the middle thyroid vein

Cervical lymph node dissection 
Table 5 (continued)

McKeown steps excluded after Delphi round 1 and 2

Creation of gastric tube

37. Oversew staple line

Cervical introduction of gastric tube and removal of specimen

38. Introduce gastric tube into thoracic cavity until you reach cervical anastomotic site by pulling esophagus/specimen through cervi- 60 cal incision

39. Introduce gastric tube into camera cover

Cervical stapled E/S anastomosis

Cervical stapled $\mathrm{S} / \mathrm{S}$ anastomosis

Cervical hand-sewn E/S anastomosis

40. Place additional sutures along this staple line.(tip gastric tube)

Cervical hand-sewn E/E anastomosis

41. Make sure proximal esophagus is open (only necessary when transection was done by stapler)

Omentoplasty

42. Perform omentoplasty at anastomotic site

Placement of drains

43. Place and secure cervical drain

Jejunostomy placement

44. Position patient in Trendelenburg

45. Place extra anti-rotational stitches

Hiatal approximation

46. Approximate hiatus

Supplementary Information The online version of this article (doi:https://doi.org/10.1007/s00464-021-08304-5) contains supplementary material, which is available to authorized users.

Acknowledgements The authors would like to thank Marja Bulte - ter Meer, PhD for providing Fig. 1 of the manuscript.

Collaborators for the MIE Delphi Collaboration M. Asif Chaudry (Department of Surgery, The Royal Marsden, Sutton), E. Cheong (Department of Surgery, Norfolk and Norwich University Hospital, Norwich), F. Daams (Department of Surgery, Amsterdam UMC, VUMC, Amsterdam), M.J. van Det (Department of Surgery, ZGT, Almelo/Hengelo), C. Gutschow (Department of Surgery, USZ, Zürich), J. Heisterkamp (Department of Surgery, ETZ, Tilburg), R. Van Hillegersberg (Department of Surgery, UMC Utrecht, Utrecht), A. Hölscher (Department of Surgery, University Hospital Cologne, Cologne), E.A. Kouwenhoven (Department of Surgery, ZGT, Almelo/ Hengelo), M.D.P. Luyer (Department of Surgery, Catharina Hospital, Eindhoven), I.S. Martijnse (Department of Surgery, ETZ, Tilburg), P. Nafteux (Department of Thoracic Surgery, UZ Leuven, Leuven), G.A.P. Nieuwenhuijzen (Department of Surgery, Catharina Hospital, Eindhoven), M. Nilsson (Division of Surgery, Karolinska University Hospital, Stockholm), P. Pattyn (Department of Surgery, UZ Gent, Gent), D.L. van der Peet (Department of Surgery, Amsterdam UMC, VUMC, Amsterdam), J.V. Räsänen (Department of Surgery, Helsinki University Hospital, Helsinki), J.P. Ruurda (Department of Surgery, UMC Utrecht, Utrecht), P. Schneider (Department of Surgery, University Hospital Zürich, Zürich), W. Schröder (Department of Surgery, University Hospital Cologne, Cologne), H. van Veer (Department of Surgery, UZ Leuven, Leuven), B.P.L. Wijnhoven (Department of Surgery, Erasmus MC, Rotterdam).

The enlisted collaborators were all part of the Delphi consensus process. They were given the opportunity to review and edit the manuscript and all approved the final version.
Funding This study has been fully supported and financed by the Radboud University Medical Center, Department of Surgery, Nijmegen, the Netherlands.

\section{Compliance with ethical standards}

Disclosures Y. Eddahchouri reports a grant from Johnson \& Johnson, outside the submitted work. F. van Workum and C. Rosman report a grant from Medtronic and from Johnson \& Johnson, outside the submitted work. M.I. van Berge Henegouwen reports a grant from Olympus Corporation and from Stryker, and he is a consultant for Johnson \& Johnson, Medtronic and Mylan N.V. outside the submitted work. All authors declare that they have no conflicts of interest regarding the submitted work. F.J.H. van den Wildenberg, F. Polat, H. van Goor, JP. E.N. Pierie, B.R. Klarenbeek and S.S. Gisbertz have no conflicts of interest or financial ties to disclose.

Open Access This article is licensed under a Creative Commons Attribution 4.0 International License, which permits use, sharing, adaptation, distribution and reproduction in any medium or format, as long as you give appropriate credit to the original author(s) and the source, provide a link to the Creative Commons licence, and indicate if changes were made. The images or other third party material in this article are included in the article's Creative Commons licence, unless indicated otherwise in a credit line to the material. If material is not included in the article's Creative Commons licence and your intended use is not permitted by statutory regulation or exceeds the permitted use, you will need to obtain permission directly from the copyright holder. To view a copy of this licence, visit http://creativecommons .org/licenses/by/4.0/. 


\section{References}

1. Bray F, Ferlay J, Soerjomataram I, Siegel RL, Torre LA, Jemal A (2018) Global cancer statistics 2018: GLOBOCAN estimates of incidence and mortality worldwide for 36 cancers in 185 countries. CA Cancer J Clin 68:394-424. https://doi.org/10.3322/ caac. 21492

2. Mu J, Gao S, Mao Y, Xue Q, Yuan Z, Li N, Su K, Yang K, Lv F, Qiu B, Liu D, Chen K, Li H, Yan T, Han Y, Du M, Xu R, Wen Z, Wang W, Shi M, Xu Q, Xu S, He J (2015) Open threestage transthoracic oesophagectomy versus minimally invasive thoraco-laparoscopic oesophagectomy for oesophageal cancer: protocol for a multicentre prospective, open and parallel, randomised controlled trial. BMJ Open 5:e008328-e008328. https ://doi.org/10.1136/bmjopen-2015-008328

3. Haverkamp L, Seesing MFJ, Ruurda JP, Boone J, Hillegersberg $R$, v. (2016) Worldwide trends in surgical techniques in the treatment of esophageal and gastroesophageal junction cancer. Dis Esophagus. https://doi.org/10.1111/dote.12480

4. Biere SS, Maas KW, Bonavina L, Garcia JR, van Berge Henegouwen MI, Rosman C, Sosef MN, de Lange ES, Bonjer HJ, Cuesta MA, van der Peet DL (2011) Traditional invasive vs minimally invasive e sophagectomy: a multi-center, randomized trial (TIME-trial). BMC Surg 11:2. https://doi. org/10.1186/1471-2482-11-2

5. Briez N, Piessen G, Bonnetain F, Brigand C, Carrere N, Collet D, Doddoli C, Flamein R, Mabrut J-Y, Meunier B, Msika S, Perniceni T, Peschaud F, Prudhomme M, Triboulet J-P, Mariette C (2011) Open versus laparoscopically-assisted oesophagectomy for cancer: a multicentre randomised controlled phase III trial - the MIRO trial. BMC Cancer 11:310. https://doi. org/10.1186/1471-2407-11-310

6. Mariette C, Markar SR, Dabakuyo-Yonli TS, Meunier B, Pezet $\mathrm{D}$, Collet D, D'Journo XB, Brigand C, Perniceni T, Carrère N, Mabrut J-Y, Msika S, Peschaud F, Prudhomme M, Bonnetain F, Piessen G (2019) Hybrid minimally invasive esophagectomy for esophageal cancer. N Engl J Med 380:152-162. https://doi. org/10.1056/NEJMoa1805101

7. Metzger R, Bollschweiler E, Vallböhmer D, Maish M, DeMeester TR, Hölscher AH (2004) High volume centers for esophagectomy: what is the number needed to achieve low postoperative mortality? Dis Esophagus 17:310-314. https://doi.org /10.1111/j.1442-2050.2004.00431.x

8. Markar SR, Karthikesalingam A, Thrumurthy S, Low DE (2012) Volume-Outcome relationship in surgery for esophageal malignancy: systematic review and meta-analysis 2000-2011. J Gastrointest Surg 16:1055-1063. https://doi.org/10.1007/s1160 5-011-1731-3

9. Brusselaers N, Mattsson F, Lagergren J (2014) Hospital and surgeon volume in relation to long-term survival after oesophagectomy: systematic review and meta-analysis. Gut 63:1393-1400. https://doi.org/10.1136/gutjnl-2013-306074

10. Birkmeyer JD, Sun Y, Wong SL, Stukel TA (2007) Hospital volume and late survival after cancer surgery. Ann Surg 245:777783. https://doi.org/10.1097/01.sla.0000252402.33814.dd

11. Claassen L, van Workum F, Rosman C (2019) Learning curve and postoperative outcomes of minimally invasive esophagectomy. $\mathbf{J}$ Thorac Dis 11:S777-S785

12. White A, Kucukak S, Lee DN, Mazzola E, Zhang Y, Swanson SJ (2019) Ivor Lewis minimally invasive esophagectomy for esophageal cancer: an excellent operation that improves with experience.
J Thorac Cardiovasc Surg 157:783-789. https://doi.org/10.1016/j. jtcvs.2018.10.038

13. van Workum F, Stenstra MHBC, Berkelmans GHK, Slaman AE, van Berge Henegouwen MI, Gisbertz SS, van den Wildenberg FJH, Polat F, Irino T, Nilsson M, Nieuwenhuijzen GAP, Luyer MD, Adang EM, Hannink G, Rovers MM, Rosman C (2019) Learning curve and associated morbidity of minimally invasive esophagectomy. Ann Surg 269:88-94. https://doi.org/10.1097/ SLA.0000000000002469

14. Pennathur A, Awais O, Luketich JD (2010) Technique of minimally invasive ivor lewis esophagectomy. Ann Thorac Surg 89:S2159-S2162. https://doi.org/10.1016/j.athoracsur .2010 .03 .069

15. Zevin B, Bonrath EM, Aggarwal R, Dedy NJ, Ahmed N, Grantcharov TP (2013) Development, feasibility, validity, and reliability of a scale for objective assessment of operative performance in laparoscopic gastric bypass surgery. J Am Coll Surg 216:955-965. e8. https://doi.org/10.1016/j.jamcollsurg.2013.01.003

16. Palter VN, MacRae HM, Grantcharov TP (2011) Development of an objective evaluation tool to assess technical skill in laparoscopic colorectal surgery: a Delphi methodology. Am J Surg 201:251-259. https://doi.org/10.1016/j.amjsurg.2010.01.031

17. Dijkstra FA, Bosker RJI, Veeger NJGM, van Det MJ, Pierie JPEN (2015) Procedural key steps in laparoscopic colorectal surgery, consensus through Delphi methodology. Surg Endosc 29:2620 2627. https://doi.org/10.1007/s00464-014-3979-7

18. Kaijser MA, van Ramshorst GH, Emous M, Veeger NJGM, van Wagensveld BA, Pierie J-PEN (2018) A Delphi consensus of the crucial steps in gastric bypass and sleeve gastrectomy procedures in the Netherlands. Obes Surg 28:2634-2643. https://doi. org/10.1007/s11695-018-3219-7

19. Graham B (2003) Delphi as a method to establish consensus for diagnostic criteria. J Clin Epidemiol 56:1150-1156. https://doi. org/10.1016/S0895-4356(03)00211-7

20. McMillan SS, King M, Tully MP (2016) How to use the nominal group and Delphi techniques. Int J Clin Pharm. https://doi. org/10.1007/s11096-016-0257-x

21. Bland JM, Altman DG (1997) Statistics notes: Cronbach's alpha. BMJ 314:572-572. https://doi.org/10.1136/bmj.314.7080.572

22. Sierles FS (2003) How to do research with self-administered surveys. Acad Psychiatry 27:104-113. https://doi.org/10.1176/appi. ap.27.2.104

23. Burns KEA, Duffett M, Kho ME, Meade MO, Adhikari NKJ, Sinuff T, Cook DJ (2008) A guide for the design and conduct of self-administered surveys of clinicians. Can Med Assoc J 179:245-252. https://doi.org/10.1503/cmaj.080372

24. Birkmeyer JD, Finks JF, O'Reilly A, Oerline M, Carlin AM, Nunn AR, Dimick J, Banerjee M, Birkmeyer NJO (2013) Surgical skill and complication rates after bariatric surgery. N Engl J Med 369:1434-1442. https://doi.org/10.1056/NEJMsa1300625

25. Curtis NJ, Foster JD, Miskovic D, Brown CSB, Hewett PJ, Abbott S, Hanna GB, Stevenson ARL, Francis NK (2020) Association of surgical skill assessment with clinical outcomes in cancer surgery. JAMA Surg. https://doi.org/10.1001/jamasurg.2020.1004,May6

26. Kramp KH, van Det MJ, Veeger NJGM, Pierie J-PEN (2016) Validity, reliability and support for implementation of independence-scaled procedural assessment in laparoscopic surgery. Surg Endosc 30:2288-2300. https://doi.org/10.1007/s0046 4-015-4254-2

Publisher's Note Springer Nature remains neutral with regard to jurisdictional claims in published maps and institutional affiliations. 